\title{
Structural Behavior of Experimented Retrofitted RC Beam Using Natural Fibers with Neural Network
}

\author{
A.S.Jeyabharathy, S.Robert Ravi
}

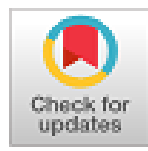

\begin{abstract}
Reinforced Concrete (RC) structures frequently need restoring or potentially strengthening, because of a difference in use, growing or disintegration of materials delivered by natural components, or material damage because of unexpected loads. One fundamental implementation of this retrofitting modernism with fiber sheets to give external detention to $R C$ structures when the limit of the existing structure is inadequate. In this paper, we present a novel experimental examination dependent on retrofitting reinforced concrete beams with regular hybrid fibers comprising of sisal and coir fiber. The concrete was blended with specific design ratio dependent on the evaluation of M20, M25, M30, and M35 grades. The specimens are cast and restored before testing. The behavior of the beams is inspected with the assistance of deflection, ductility, Load Carrying Capacity (LCC), and Energy Absorption Capacity (EAC). The experimental outcomes were investigated with simulation modeling that has been completed to simulate the behavior of the considerable number of beams. For validation purpose, we have utilized Artificial Neural Network (ANN) with structure optimization process. The optimal result is finding out by comparing the retrofitted specimen into control specimens. The result found that hybrid fiber retrofitted specimen performs low deflection and ductility at high loads and then increase the LCC and EAC compared to Control beams (CB1 and CB2). The soft computing strategies decrease computational time and limit the expense in a compelling way.
\end{abstract}

Keywords : hybrid fibers, retrofitted beam, control beam, deflection, ductility, LCC and EAC

\section{INTRODUCTION}

In the construction field Reinforced Concrete (RC) is the most extraordinary materials on the world [1]. These days, scientists give more regard for concentrate the behavior of RC beam, in view of its load carrying capacity just as ductility [2]. Also, when the RC beam is exposed to seismic loading, it can't certainly withstand due to its low quality particularly at the time of catastrophic events like quake, and so on [3]. In such conditions, there are two arrangements called as a replacement and retrofitting [4].

Revised Manuscript Received on October 30, 2019.

* Correspondence Author

A.S.Jeyabharathy A.S.JEYABHARATHY received the B.E. degree in Civil Engineering from K.S.R College of engineering, research scholar in Karunya University, Coimbatore

Dr. S. Robert Ravi, Professor in Department of Civil Engineering from ACE Engineering College, Ghatkesar, Hyderabad.

(C) The Authors. Published by Blue Eyes Intelligence Engineering and Sciences Publication (BEIESP). This is an open access article under the CC BY-NC-ND license (http://creativecommons.org/licenses/by-nc-nd/4.0/)
In the proposed investigation, retrofitting idea is played a noteworthy job in the RC beam groundwork. Retrofitting is only can shield a harmed basic component from further physical-substance ecological animosity [5].

The diverse approaches to retrofit the RC beam are, concrete jacketing, Fiber Reinforced Polymers (FRPs) wrapping and the utilization of steel sections or hindquarters [6]. In the most recent decades, the utilization of FRP based retrofitting the basic component has turned out to be increasingly more across the board [7] in view of its great attributes, for example, simply to introduce, insusceptibility to consumption and high quality $[8,9]$. The utilization of FRP wraps is helpful and the expansion in the measure of the beam is insignificant. FRP composite materials likewise offer an appealing option in contrast to some other retrofitting system in the field of fix and reinforcing of concrete components [10]. The most generally utilized fibers, which are utilized as reinforcements in FRP, for the reinforcing of concrete structures are artificial fibers which are carbon, glass, and aramid, and so on $[11,13]$. In addition, the utilization of some regular fibers, for example, coir fibers, jute fibers and sisal fibers which are locally accessible materials, in the field of auxiliary retrofitting [12]. Monetary and other related factors in many creating nations where characteristic fibers are plentiful interest that researchers and specialists apply fitting innovation to use these common fibers as viable and financially as workable for auxiliary upgradation and furthermore different purposes for lodging and different needs, and so forth [14]. Fundamentally, carbon fiber is one of the costliest of the considerable number of fibers, trailed by aramid fibers, and despite the fact that it accompanies leverage of expanding the basic potential by numerous folds, [15] it likewise comes at an overhead of tremendous cost and cost, and thus can't be effectively considered as a decent result based market item. Here an attempt is made to study the conceivable outcomes of utilizing a few fibers like glass, carbon, basalt, aramid, steel, banana, jute and coconut materials as fiber reinforced polymer [16], in structural retrofitting of reinforced concrete beams, which attempts to improve the basic properties of the RC beams [17]. This work is to examine the behavior and mechanical properties of RC beams retrofitted with FRP, utilizing experiments with distinctive specimens. 
The upcoming zone of the paper is dealt with as seeks after: Section 2 depicts the review of existing literature identified with our proposed model; Section 3 maps the novel system part and the subsection of section 3 shows the explanatory portion of the proposed model. Section 4 inspected the consequence of experimental and simulation modeling. Section 5 gives the conclusion section with the future scope.

\section{EXISTING LITERATURES}

In 2013 A.S. Jeyabharathy and S. Robert Ravi [18] had presented the ductility behavior and absorption capacity of fiber retrofitted RC beam. In the examination, fibers like sisal, vakka, and banana and so on were utilized to make fiber sheets for retrofitting the structural component. Three reinforced concrete beam specimens as two control specimens and one retrofitted specimen were thrown. The static load was connected at the highest point of the beam up to a controlled load. Finally, the execution of retrofitted specimens was compared with control specimens. In 2014 Sen, T. also, Reddy, H.J., [19] had analyzed the elastic and flexural behavior of Sisal based FRP composite component and contrast with carbon and glass based FRP composite structure. Furthermore, the work incorporates the investigation of disappointment modes, flexural reinforcing impact on extreme load conveying limit and load-deflection behavior of RC beams fortified slightly with SFRP, CFRP, and GFRP. The outcomes exhibited that the sisal based wrapping was great in flexural and load deflection contrasted with CFRP and GFRP. In 2011 Sen, T. and, Reddy, H.J., [20] contemplated strengthening of RCC beam utilizing a characteristic fiber. A nonlinear finite element examination was completed so as to assess the execution of Bamboo fibers in structural retrofitting by retrofitting a Plain Concrete Block by utilizing Bamboo fiber reinforced polymer. It was seen that the strengthened specimens showed a noteworthy increment in quality, stiffness, and reliability when contrasted with controlled specimens.

[21] The elastic static examination of composite beams made of two structural segments consistent with jolts, (for example, composite concrete-steel beams) or with a layer of a sticky material, (for example, beams retrofitted with FRP overlays) stretching out along the beam length was exhibited by Areiza-Hurtado, M. and, Aristizábal-Ochoa, J.D., 2017. Three complete precedents were displayed and the determined outcomes were contrasted and diagnostic and experimental outcomes accessible in the specialized literatures introduced by different researchers. In 2018 Duic, J., et al. [22] had been assessed the execution of concrete beams reinforced with basalt fiber composite rebar. Full-scale tests on eight extensive scale concrete beam specimens reinforced with either BFRP rebars or steel rebars were embraced. The test information was broken down to assess the execution of BFRP rebar reinforced concrete beams in shear and flexure. It was discovered that at a low support proportion, BFRP rebar reinforced beams displayed more flexural and shear breaking than partner steel rebar reinforced concrete beams. Wang, P., et al. [23] represented a seriously harmed Lattice-Core Sandwich Cylinder (LSC) was retrofitted by the carbon fiber reinforced composite (CFRC) overlay through wrapping and riveting plans. Free vibration and unipivotal pressure tests were done to uncover their mechanical exhibitions. Extreme load of the fixed cylinder is minimal littler than of the unblemished cylinder. In this manner, it exhibited the retrofitting plan was compelling to re-use the severally harmed CFRC LSC. In 2018 Valente, M. and Milani, G., [24] proposed a rearranged displacement based technique utilizing non-direct static investigations was connected to acquire a primer estimation of the general insufficiency of an under-structured four-story RC frame and to propose reasonable retrofitting mediations dependent on various rehabilitation methodologies. To this point, precise numerical models were created to reenact the seismic reaction of the RC frame in the first and retrofitted arrangements. The viability of three distinctive retrofitting solutions countering the primary basic inadequacies of the $\mathrm{RC}$ frame was assessed through the displacement based methodology.

\section{A. Motivation of the study}

In the structural building industry, new imaginative materials/advances are introduced to congregate the necessities of highly developed infrastructure. Any innovation or material has its restrictions and to meet the new prerequisites and new advancements must be created and utilized. Recently, beams may not meet all requirements to current seismic necessities and in this manner, retrofitting of these structures is fundamental. The retrofitting is a standout amongst the best choices to make an existing insufficient building safe against future tremor or other natural disasters. The most straightforward approach to strengthen the beam is to enclose fiber by two orthogonal directions. An endeavor has been made to do an examination concerning the behavior of retrofitted reinforced concrete beam specimens retrofitted with various fiber wrapping sheets.

\section{A NOVEL APPROACH OF RETROFITTED RCC BEAM: PROPOSED METHODOLOGY}

The scope of this examination is to determine the behavior of RCC beam retrofitted with various fiber sheets by utilizing experimental and simulation modeling. This examination comprises of three diverse reinforced concrete beams, for example, two control beams and one retrofitted beam. The beams are demonstrated with various fiber sheets; the fibers perform as an eco-environmental nature, nonabrasive, high explicit quality, and genuinely great mechanical properties. The beams are loaded up to $10 \mathrm{kN}$ and discover the deflection, ductility, Load Carrying Capacity (LCC) and Energy Absorption Capacity (EAC). To improve the execution of the examination, the validation experiences by utilizing machine learning algorithms, for example, ANN. The ideal outcome is discovering by comparing the retrofitted specimen into control specimens.

\section{A. Experimental Investigation}

The experimental examination comprises of three reinforced concrete beams recognized by the standard specification, for example, CB1-IS 456:2000 (Control), CB2-IS 13920-1993 (Control) and RB-IS 456:2000 (retrofitted) with determined dimensions. The components of the beam appear in figure 1 . In the experimental modeling, the beam is retrofitted with different common fiber sheets, for example, sisal, coir, and hybrid fiber (sisal + coir). 
This examination is done for every fiber related to RB1 and finds the optimal fibers which perform as high quality and performance.
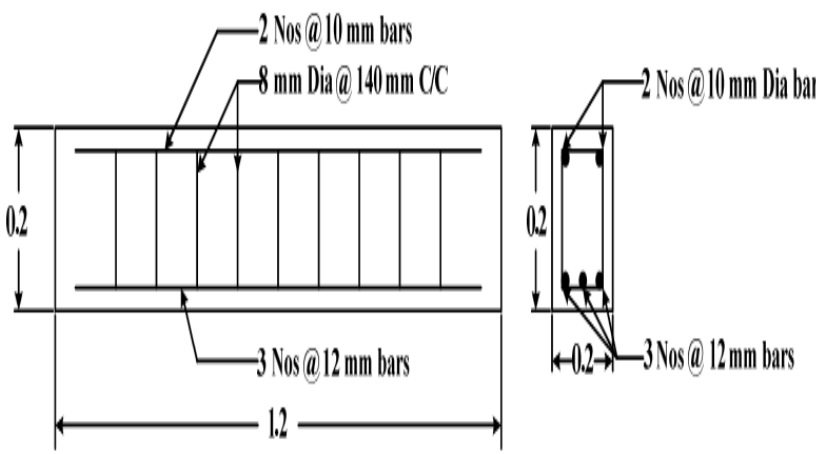

(a)

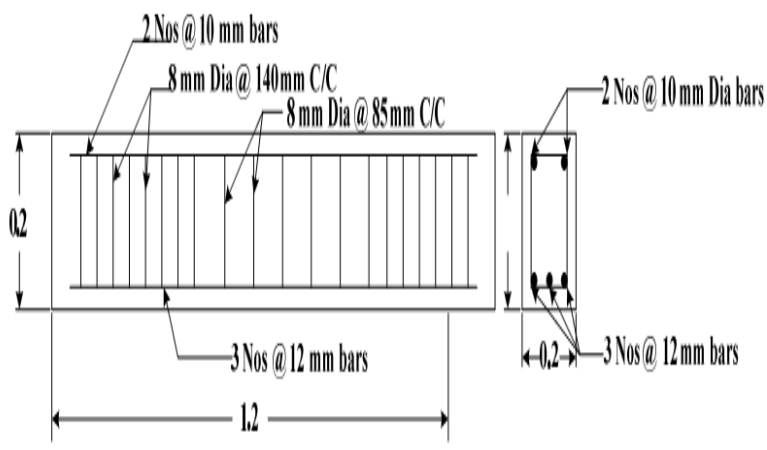

(b)

Fig. 1. Dimensions of proposed specimens (a) Control specimen (b) Retrofitted Specimen

\section{Mix Design}

The concrete was blended in the design ratio of 1:1.5:3.17 and the evaluation utilized as M20, M25, M30, and M35. The specimens are cast and cured before testing. Here, $\mathrm{M}$ represents Mix and the number represents trademark compressive strength of the concrete in 28 days in the direct pressure test. For instance, if the proportion for M20 concrete is 1:1.5:3 then 1 section cement, 1.5 part sand and 3 section aggregate (smashed stone) in volume is bunched for blending. The Code of training for plain and reinforced concrete was arranged and tried by IS 456 - 2000 standard and IS 13920-1993, and the retrofitted beam are set up as indicated by IS 456:2000. By the blend of these reinforced concrete discrete fiber sheets are retrofitted; the fibers, for example, sisal fiber and coir fiber. These fibers are shabby and give the concrete mechanical, compound and warm obstruction. The blending specimen subtleties appear underneath table 1.

Table- I. Specimen details

\begin{tabular}{|c|c|c|c|}
\hline S. No & $\begin{array}{c}\text { Speci } \\
\text { men }\end{array}$ & Description & Notations \\
\hline 1 & CB1 & $\begin{array}{c}\text { Control } \\
\text { specimen 1 }\end{array}$ & $\begin{array}{c}\text { CB1 - (IS } \\
456: 2000)\end{array}$ \\
\hline 2 & CB2 & $\begin{array}{c}\text { Control } \\
\text { specimen 2 }\end{array}$ & $\begin{array}{c}\text { CB2 - (IS } \\
13920-1993)\end{array}$ \\
& 1 & $\begin{array}{c}\text { HFRB 1-SFRB } \\
\text { Reinforced } \\
\text { Beam }\end{array}$ & \\
\hline 3 & SFRB & \\
\hline
\end{tabular}

\begin{tabular}{|c|c|c|}
\hline 4 & $\begin{array}{c}\text { CFRB } \\
1\end{array}$ & $\begin{array}{c}\text { Coir Fiber } \\
\text { Reinforced } \\
\text { Beam }\end{array}$ \\
\hline 5 & HFRB & $\begin{array}{c}\text { Hybrid fiber } \\
\text { Reinforced } \\
\text { Beam 1 }\end{array}$ \\
& 1 & . \\
\hline
\end{tabular}

Specimen Preparation: Retrofitting of beams

Concrete was blended in a tilting type mixer machine and was appropriately set and compacted. The sides of the mould were expelled 24 hours subsequent to casting and the test specimens were restored in water for 28 days. Before wrapping the fiber sheet, the essences of the specimen were ground precisely to evacuate the laitance. Each of the voids was loaded up with putty. At that point, a two-segment primer framework was applying on the concrete surface and permitted to a solution for 24 hours. A two-segment epoxy covering was then connected on the primer covered surface and an inward layer of fiber sheet and promptly folded around the bottom and side surface of the reinforced concrete beam. A hand roller was then applied tenderly over the wrap with the goal that great attachment was accomplished between the concrete surfaces and permitted to remedy for seven days. Another layer of the two-part epoxy was connected over the inward layer of the fiber sheet. At that point, the external layer of the wrap was connected after a similar strategy and permitted to remedy for a further time of seven days. Both the wrapped layers were symmetrical to one another.

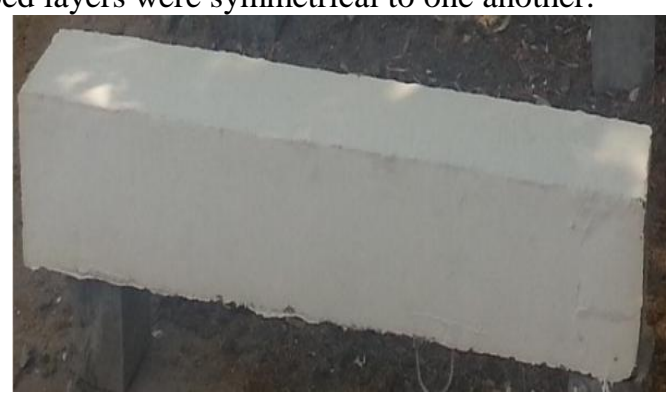

(a)

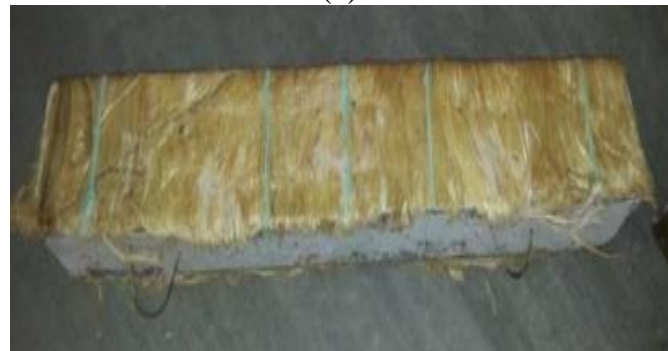

Fig. 2. Typical view of specimens (a) Control specimen (b) fiber sheet wrapped specimen

\section{Test setup}

The specimens were experimented in a loading frame in the even plane. Both the ends of the section were pivoted utilizing roller plates. The axial load was connected toward one side the segment utilizing a water-powered jack and the load was estimated utilizing an electrical load cell. The opposite end of the column was upheld by the steel bulkhead connected to the loading frame.

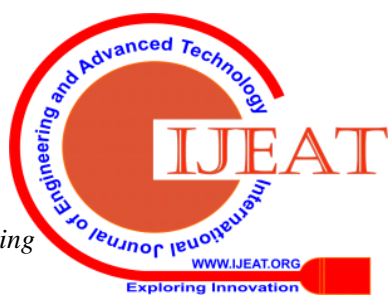




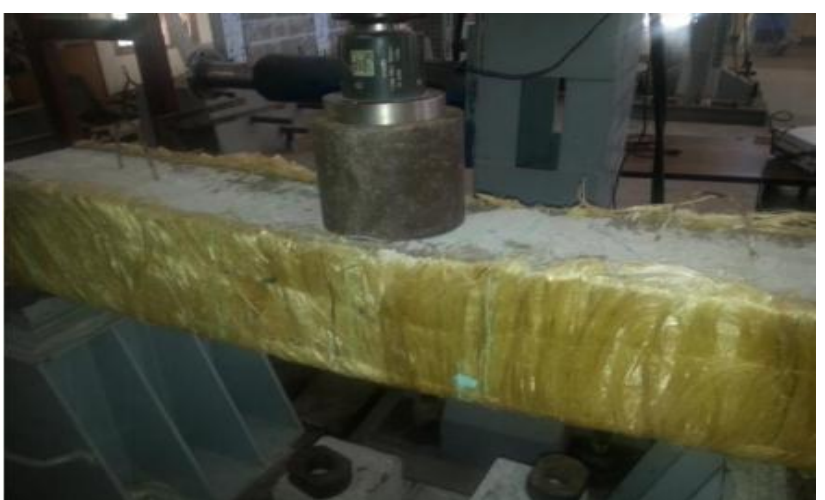

Fig. 3. Test set up of the retrofitted specimen

A transverse push and pull load were connected at the free end of the beam through a push and pull hydraulic jack off to build up a bending moment at the joint. The load on the beam was additionally estimated utilizing a load cell. The deflection at the free end of the beam was recorded at normal load intervals.

\section{B. Validating the performance using machine learning algorithms}

Subsequent to designing the model, exhibitions are anticipated utilizing machine learning algorithms in MATLAB workbench. The algorithms analyzed the performance of every specimen and anticipate the quality of retrofitted specimen utilizing fiber sheets. With the aim of augmenting the accuracy of prediction, we go for the machine learning procedure like ANN with optimization approach. Here, ANN with OCSO algorithm is utilized to anticipate the execution of retrofitted beams. Figure 4 demonstrates the ANN layers with optimizing algorithm.

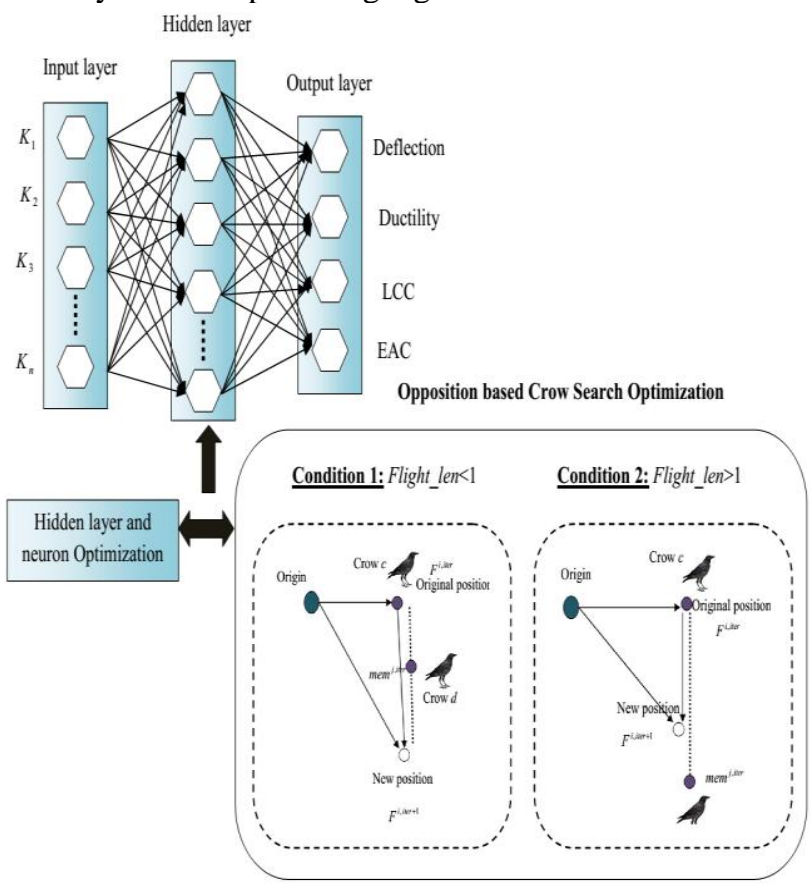

Fig. 4. ANN Layers with OCSO

\section{Artificial Neural Network (ANN)}

ANN is planned to simulate the behavior of biological frameworks made out of "neurons". It is physical cellular frameworks, which can procure, store and use experiential information. At the point when a neural network is nourished with data in the input layer, the qualities are sent to at least one node in the following layer. These nodes perform [25-26] estimations on the qualities they get and forward the outcomes to at least one node in the following layer, which rehashes the procedure. Figure 5 demonstrates the example structure of ANN which is acquired in the simulation procedure.

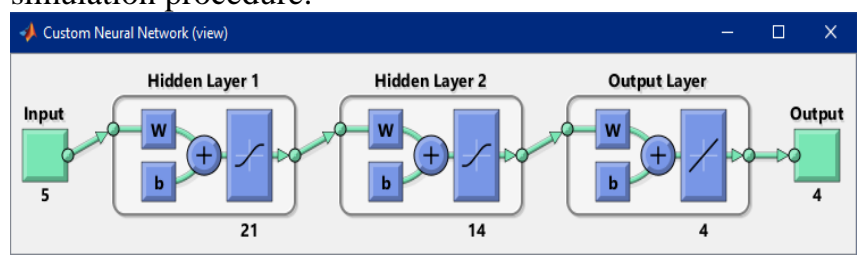

Fig. 5. Sample view of ANN structure

Input layer- In this layer, we initialize the input parameters such as load, Young's modulus, density, tensile strength and the mix proportions of every grade (M20, M25, M30, and M35) for each specimen. Where $K_{i}$ indicates the input parameters $K_{i}=\left\{K_{1}, K_{2}, K_{3}, \ldots \ldots . K_{n}\right\}$

Hidden layer- Here, the input layer weight $\alpha_{x}$ and the hidden layer weights $\beta_{x y}$ are initialized in this layer. The basic and activation function of the ANN structure is assessed by using the equation (1).

$$
H_{b}=\sum_{j=1}^{N} K_{i} \times \beta_{i j} \quad H_{a}=\sum_{x=1}^{l} \frac{1}{1+\exp \left(-H_{b}\right)}
$$

Where $H_{b}$ symbolizes the basis function; $H_{a}$ symbolizes the activation function, and $N$ refers to the number of data. Equation (1) derives the fitness function to evaluate the performance with MSE.

Fitness evaluation:Evaluate the fitness value of every solution and then ascertain the best solution values. Here, we accept the ideal fitness as the least error rate compared with experimental and other existing methodologies.

Fitness_fun $=\min \left(\frac{\sum_{i=1}^{Z_{N}}\left(A_{i}-M_{i}\right)^{2}}{Z_{N}}\right)$

Where, Fitness _ fun refers to the Fitness function, $A_{i}$ represents the actual value i.e. experimental result, $M_{i}$ signifies the predicted value, and $Z_{N}$ represents the number of data. In light of the condition (2), the minimum error rate can be accomplished by upgrading the structure utilizing the algorithm in an activation function.

Structure optimization using OCSO (Hidden Layer and Neuron)

To improve the quality of the neural network models, structure optimization of these networks is performed with respect to MSE rate. The hidden layer and neuron are optimized using the OCSO algorithm and such that error can be minimized. In this hidden layer, we have 5 layers with 30 neurons; by optimizing this structure we get an optimal structure with the optimal output. 


\section{Oppositional Crow Search Optimization (OCSO)}

CSO: CSO is an enduring meta-heuristic algorithm which is created by Askarzadeh, which is roused by the insight behavior of crows [27-28]. The CSO procedure imitates the behavior led by crows of covering up and recuperating the additional food. In view of the crow's behavior, the standards of CSO are portrayed as (a) They live as a flock, (b) they remember food concealing spots, (c) to do stealing, they pursue each other alongside (d) by probability, and they shield their reserves from being stolen.

OCSO: Improving the effectiveness of regular CS algorithm, the opposition procedure is incorporated with it. At first, we instate the hidden layer and neurons and the input parameters.

For each initialized solution, it's relating opposite function is produced. By comparing two solutions (CS populace and OCS populace), the better one is picked for further assessment. For instance, let $b \in(m, n)$ is a real number. By applying the opposite point definition, it very well may be composed as

$$
\tilde{b}_{j}=m_{j}+n_{j}-b_{j}
$$

Generate new position: Expect the crow $c$ needs to produce another position; this is finished by arbitrarily choosing one of flock crow, for example, crow $d$ likewise, its position and memory. The new position of crow is accomplished by the accompanying condition (6).

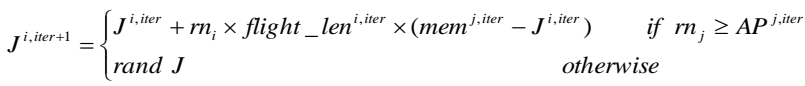

The expansion of equation (6) is: $r n_{i}$ and $r n_{j}$ indicates a random number of crow $c$ and $d$ respectively, between [0 and 1], flight_len ${ }^{i, \text { iter }}$ represents flight length of crow $c, J$ symbolizes the position of crow, mem $^{j, i t e r}$ denotes the memory location of $j^{\text {th }}$ crow and $A P^{j, \text { iter }}$ indicates the awareness probability of crow $\mathrm{j}$ at iteration.

If the new position of a crow is achievable, the crow refreshes its position. Something different, the crow stays in the present position and does not move to the created new position.
Pursued by, the fitness value for the updated position is resolved.

Memory Update: For the recently updated crow's position, its memory value is likewise updated utilizing condition (7).

$$
\mathrm{mem}^{i, \text { iter }+1}= \begin{cases}F^{i, \text { iter }} & f\left(F^{j, \text { iter }+1}\right)>f\left(\mathrm{mem}^{j, \text { iter }}\right) \\ \text { mem }^{i, \text { iter }} & \text { otherwise }\end{cases}
$$

Optimal Hidden layer and neuron of OCSO: It is seen that, if the fitness function value of the new position of a crow is better than the remembered position, the crow refreshes its memory by the new position. At the point when the most extreme iteration is met, the best position of the memory regarding the objective function value (least error) is accounted for as the ideal arrangement of the retrofitted

Output layer:In this output layer, the optimal hidden layer neurons are associated with the output layer by the neurons. Every association has a weighted value, for example, $\alpha_{1}, \alpha_{2}, \ldots \ldots . \alpha_{n}$. The basis function of the output units is communicated by and the output is deflection, ductility, LCC and EAC of every specimen.

$$
L_{\text {output }}=\sum_{i=1}^{n} \alpha_{i}\left\{\text { Fitness }_{-} \text {fun }_{i_{-} \text {optimal }}\right\}
$$

In this layer, we obtain the optimal output of retrofitted beams. The validation of this simulation modeling reduces the MSE rate compared with existing approaches.

\section{COMPUTATIONAL RESULTS}

In this section talked about the result of experimental and simulation modeling of proposed retrofitted beams. The simulation procedure is completed in the working stage of MATLAB 2016a with 4GB RAM and i5 processor. Validation of the simulation results for the deflection; ductility, LCC and EAC of 20 specimens were performed utilizing experimental data. The anticipated outcomes are compared with experimental and other existing algorithms.

\begin{tabular}{|c|c|c|c|c|c|c|c|c|c|}
\hline \multirow[t]{2}{*}{ Grade } & \multirow{2}{*}{$\begin{array}{c}\text { Spec } \\
\text { ime } \\
n\end{array}$} & \multicolumn{2}{|c|}{ Deflection (mm) } & \multicolumn{2}{|c|}{ Ductility (mm) } & \multicolumn{2}{|c|}{ LCC (kN) } & \multicolumn{2}{|c|}{ EAC $(\mathbf{k N}-\mathbf{m m})$} \\
\hline & & Experimental & ANN-OCSO & Experimental & ANN-OCSO & Experimental & ANN-OCSO & Experimental & $\begin{array}{c}\text { ANN-O } \\
\text { CSO }\end{array}$ \\
\hline \multirow[t]{5}{*}{ M20 } & CB1 & 7.59 & 7.730 & 7.52 & 6.838 & 42 & 45.165 & 65 & 65.81 \\
\hline & CB2 & 6.78 & 7.119 & 6.3 & 6.013 & 49 & 54.322 & 69 & 74.60 \\
\hline & $\begin{array}{c}\text { SFR } \\
\text { B1 }\end{array}$ & 5.8 & 6.586 & 5.9 & 5.107 & 53 & 54.328 & 72 & 78.40 \\
\hline & $\begin{array}{c}\text { CFR } \\
\text { B1 }\end{array}$ & 4.62 & 4.935 & 5.2 & 3.763 & 59 & 59.913 & 83 & 85.19 \\
\hline & $\begin{array}{c}\text { HFR } \\
\text { B1 }\end{array}$ & 2.65 & 3.471 & 4.5 & 2.325 & 64 & 66.201 & 98 & 110.52 \\
\hline \multirow[t]{4}{*}{ M25 } & CB1 & 6.6 & 6.564 & 7.7 & 6.251 & 45 & 46.418 & 66 & 65.70 \\
\hline & CB2 & 7.32 & 6.869 & 6.4 & 5.663 & 51 & 51.091 & 69.06 & 66.49 \\
\hline & $\begin{array}{c}\text { SFR } \\
\text { B1 } \\
\end{array}$ & 5.78 & 6.181 & 5.99 & 5.183 & 53.32 & 53.999 & 74 & 69.19 \\
\hline & $\begin{array}{c}\text { CFR } \\
\text { B1 }\end{array}$ & 4.52 & 5.136 & 5.4 & 4.670 & 60.03 & 59.855 & 83.36 & 78.65 \\
\hline
\end{tabular}

\section{A. Validation Analysis}

Table- II. Validation results of proposed parameters 
Structural Behavior of Experimented Retrofitted RC Beam Using Natural Fibers with Neural Network

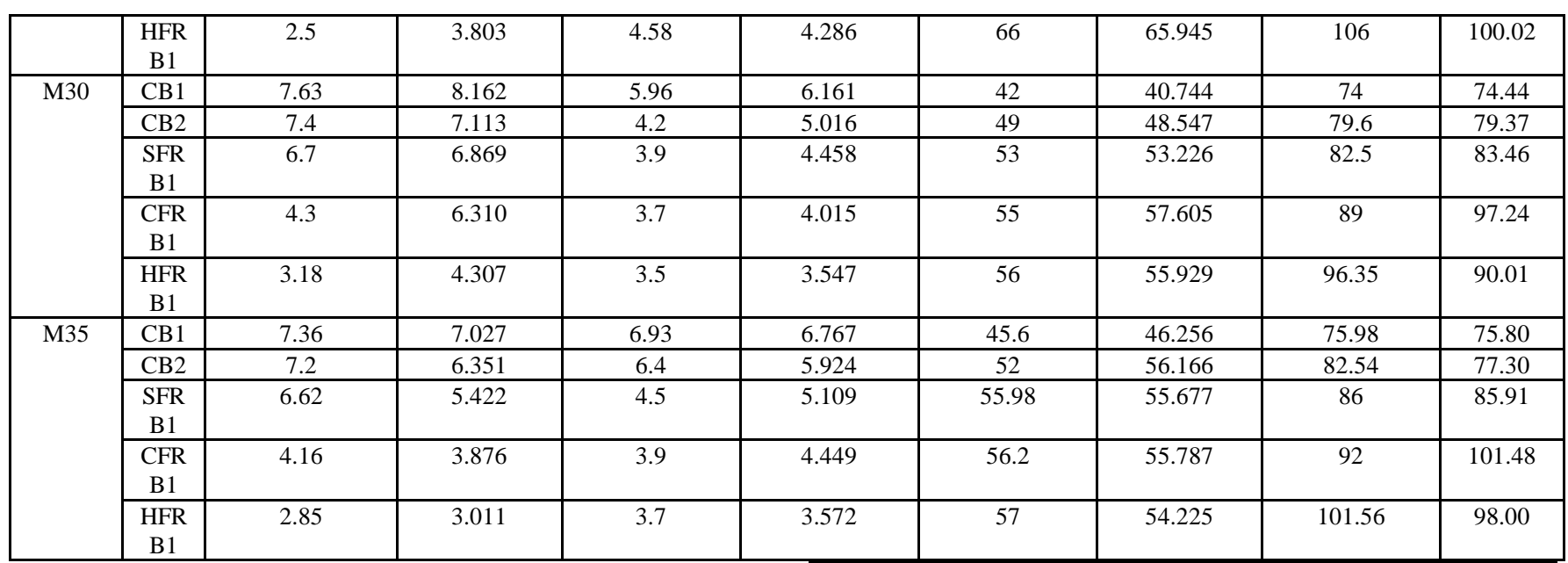

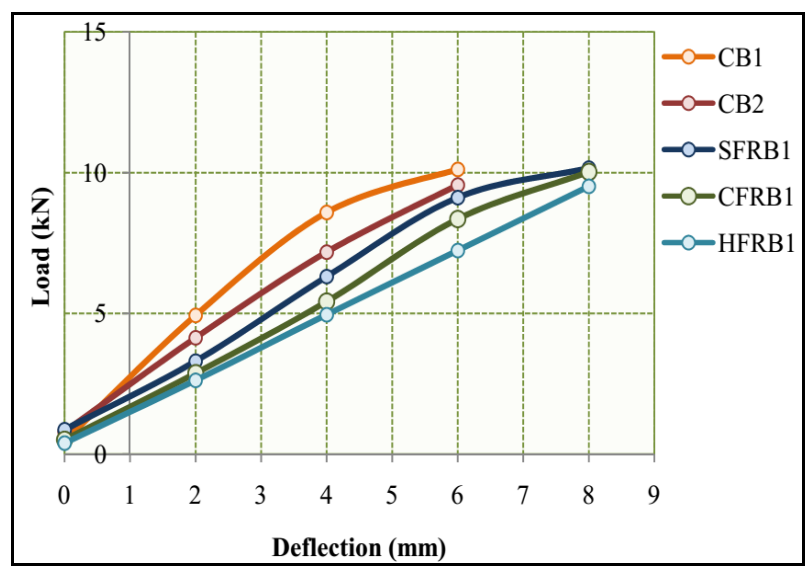

(a)

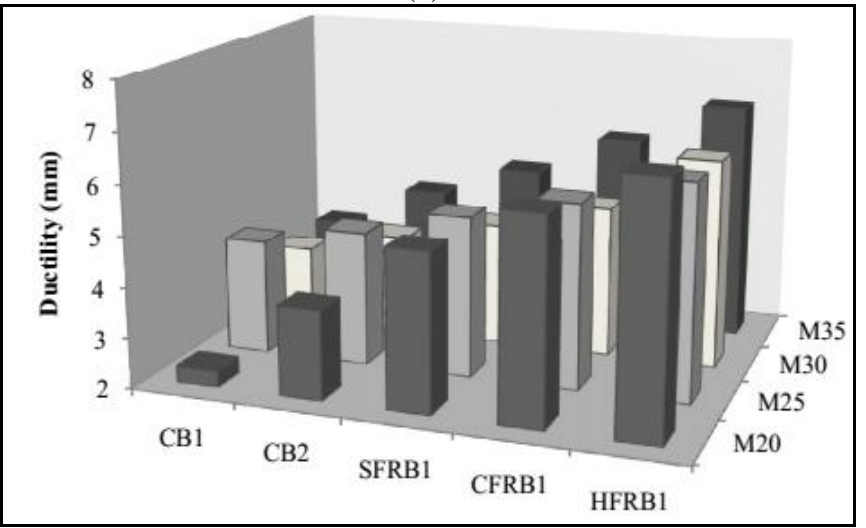

(b)

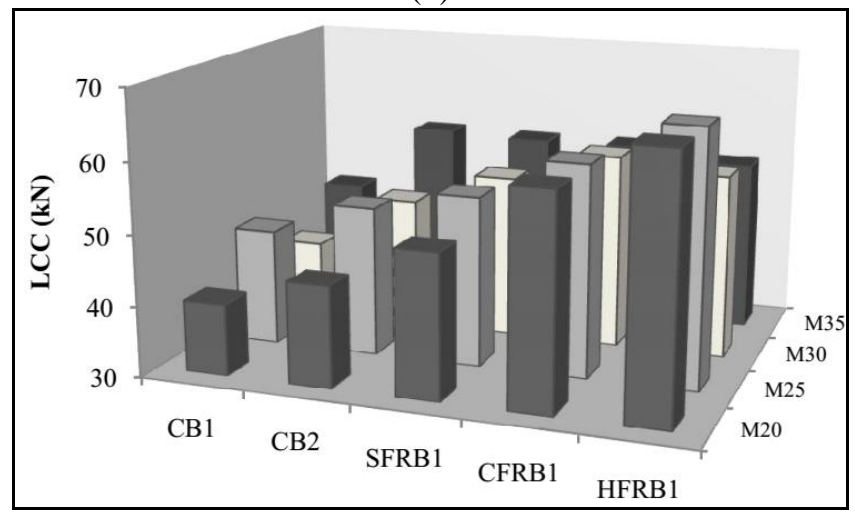

(c)

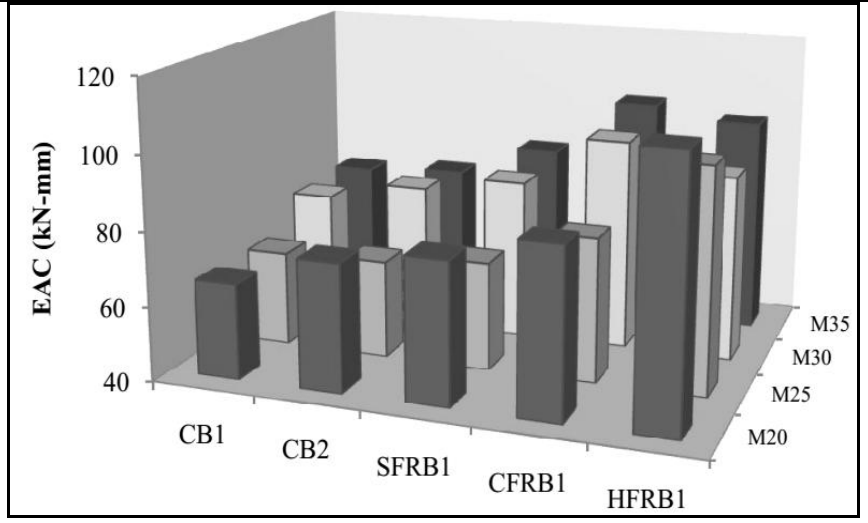

(d)

Fig. 6. Behavior analysis of proposed model (ANN-OCSO) a) load vs. Deflection (b) Ductility for all grades (c) LCC (d) EAC for all five specimens

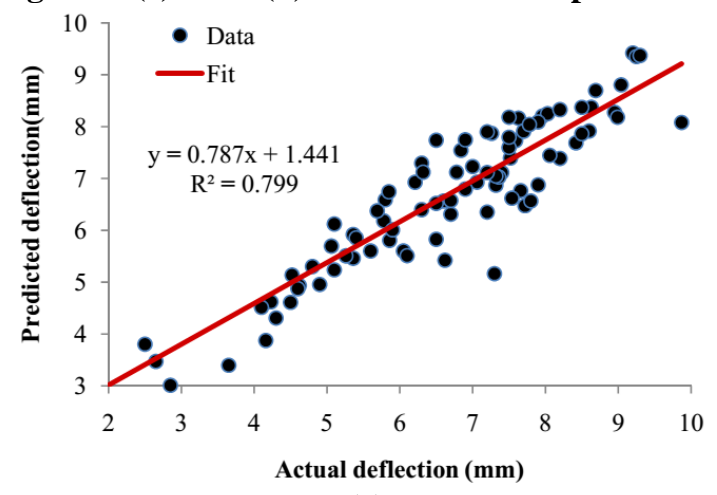

(a)

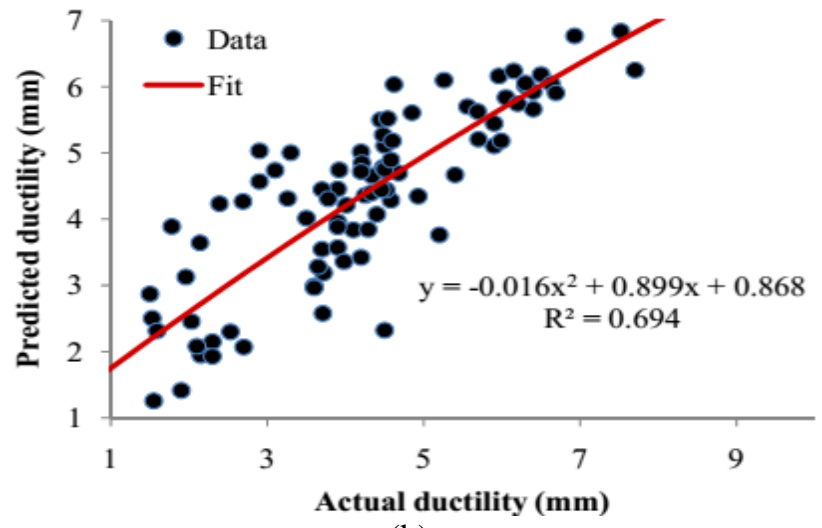

(b)

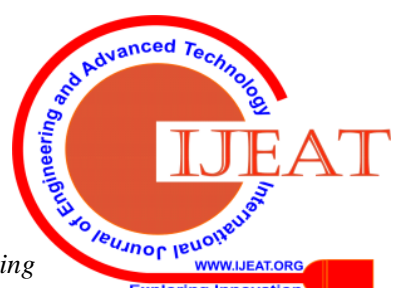




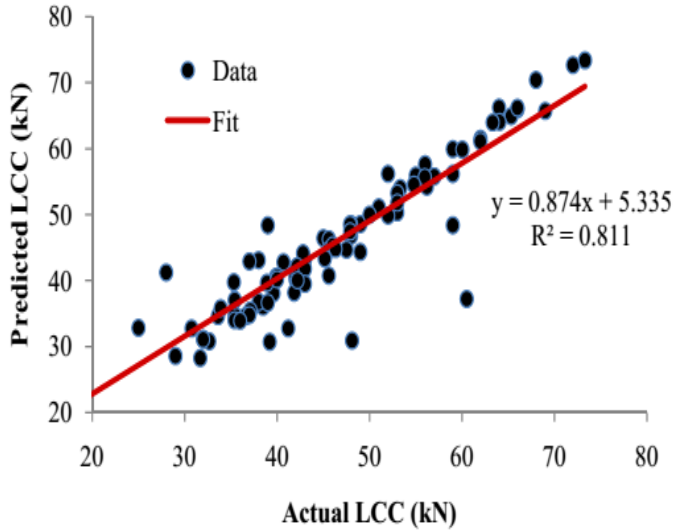

(c)

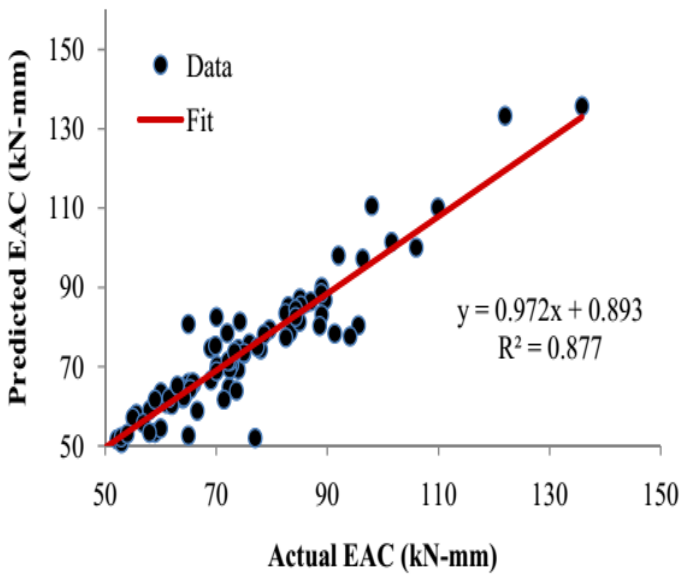

(d)

Fig. 7. Correlation analysis (a) deflection (b) Ductility (c) Load carrying capacity (d) Energy Absorption capacity

\section{B. Comparison Analysis}

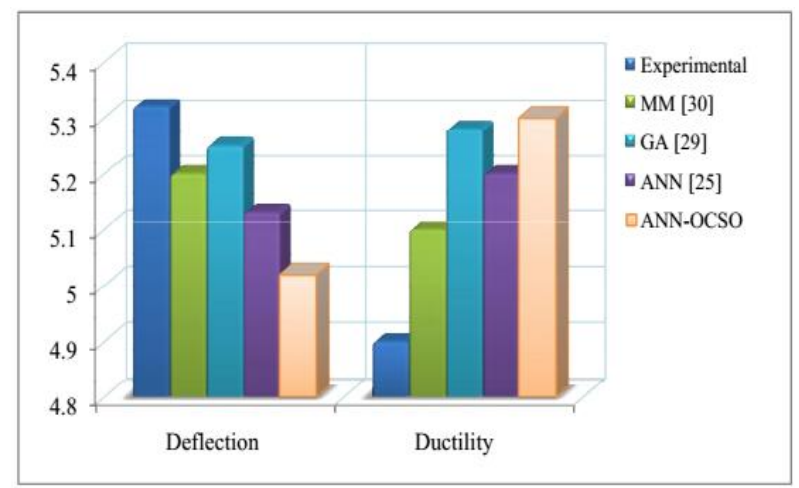

(a)

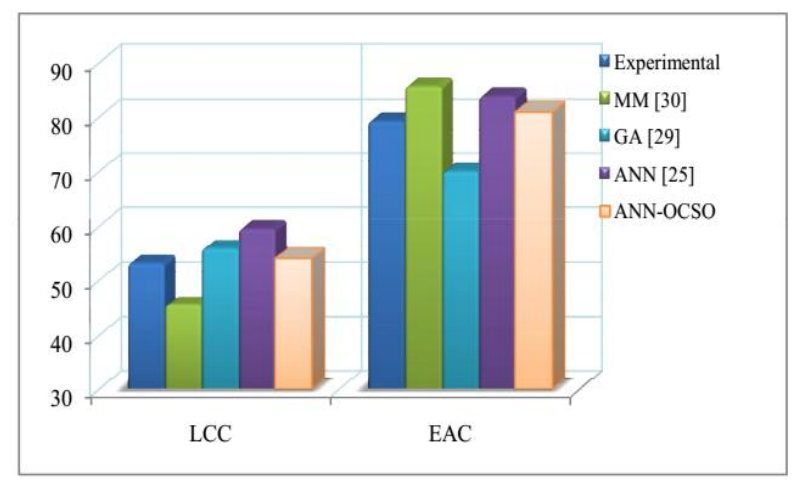

(b)

Fig.7. Comparison analysis of proposed and existing techniques (a) Deflection \& ductility (b) LCC \& EAC
Table 2 shows the validation result of the proposed study. In the case of control specimens, the crack was formed in the beam by increasing load in the range of $10 \mathrm{kN}$. The increased load widens the cracks in the control specimens CB1 and CB2; it receives high deflection after $10 \mathrm{kN}$. Then the load was stopped after the beam reaches deformation. But in retrofitted beam reduces the deflection and ductility rate because of the wrapped fiber sheet. The wrapped fibers such as sisal and coir individually perform a solution but it doesn't givean optimal solution. In the case of hybrid retrofitted specimen HFRB1, the result shows that low deflection and ductility nearly the difference maintained as in the range of 2.13\%. In similar, Load carrying capacity and Energy absorption capacity performs higher strength in the hybrid retrofitted specimen. The wrapped specimen reduces the failure rate and gets higher strength for all grades (M20, M25, M30, and M35). Coming to the validation result, ANN predicted the result accurately with the help of structural optimization. The predicted results are nearly equal to the experimental result. The error can be minimized compared to other techniques and ANN performed individually other than structure optimization. The predicted results are graphically shown in figure 6 (a), (b), (c) and (d). The comparative analysis of the proposed study is visualized in the bar graph (figure 7). This comparison depicts an optimal result in ANN with OCSO compared to separate ANN.

\section{CONCLISION}

In the proposed novel study, the beams are retrofitted with fiber sheets and analyze the behavior of the specimens particularly for M20, M25, M30, and M35. The experimental investigation concludes that the retrofitted specimens reduced the deflection range by increased loads compared to CB1 and CB2. But in the case of hybrid retrofitted beams the load carrying capacity expands; the initial crack attains in higher loads. The experimental result found that retrofitting with hybrid fiber is more valuable than sisal and coir fiber; it reduces the deflection but increases the load carrying capacity, ductility, and energy absorption capacity. In simulation modeling, the results are predicted based on ANN with OCSO algorithm. It outperforms a better prediction rate that means the algorithm gives optimal result and minimum MSE rate. The differences between the experimental and predicted results are given as $0.07 \%$; it means the proposed algorithm predicts the results accurately when compared to existing and separate ANN. The simulation examination decreases the costs and sparing the examination time period. Also, it ought to be noticed that all retrofitted specimens accomplished or surpassed a deflection, ductility limit, which might be a satisfactory exhibition level for everything except the most serious seismic loading. Later on, we will give a thought regarding strengthen the specimen with artificial fibers and exploring the execution utilizing imaginative soft computing methodologies.

\section{REFERENCE}

1. W.Wang, N.Chouw, "Behaviour of CFRC beams strengthened by FFRP laminates under static and impact loadings," Construction and Building Materials, 2017, 155, pp. 956-964. 
2. W.Zhang, H.Zhang, X. Gu, and W. Liu, "Structural behavior of corroded reinforced concrete beams under sustained loading," Construction and Building Materials, 2018, 174, pp. 675-683.

3. Bairavi and Muthuramu, "Retrofitting of RC elements using basalt fiber", Journal of Innovations in Engineering and Technology, 2018, 6(4), pp. 87-93.

4. A.A. Mostafa, and A.G.Razaqpur, "Finite element model for predicting post delamination behaviour in FRP-retrofitted beams in flexure," Construction and Building Materials, 2017, 131, pp. 195-204.

5. G. Ruano, F. Isla, , R.I. Pedraza, D. Sfer, and B. Luccioni, "Shear retrofitting of reinforced concrete beams with steel fiber reinforced concrete," Construction and Building Materials, 2014, 54, pp. 646-658.

6. K. Bicer, H. Yalciner, A.P. Balkıs, and A. Kumbasaroglu, "Effect of corrosion on flexural strength of reinforced concrete beams with polypropylene fibers," Construction and building materials, 2018, 185, pp. 574-588.

7. H.S. Kim, and Y.S.Shin, "Flexural behavior of reinforced concrete (RC) beams retrofitted with hybrid fiber reinforced polymers (FRPs) under sustaining loads," Composite structures, 2011, 93(2), pp. 802-811.

8. C. Ma, D Wang, And Z. Wang, "Seismic retrofitting of full-scale RC interior beam-column-slab subassemblies with CFRP wraps," Composite Structures, 2017, 159, pp. 397-409.

9. T. Sen, and H.J. Reddy, "Efficacy of bio derived jute FRP composite based technique for shear strength retrofitting of reinforced concrete beams and its comparative analysis with carbon and glass FRP shear retrofitting schemes" Sustainable Cities and Society, 2014, 13, pp. 105-124.

10. H.R. Tavakoli, P. Jalali, and S. Mahmoudi, "Experimental evaluation of the effects of adding steel fiber on the post-cyclic behavior of reinforced self-compacting concrete beams," Journal of Building Engineering, 2019, 100771.

11. A. Mostafa, and A.G.Razaqpur, "A nonlinear model for predicting intermediate crack-induced debonding in FRP-retrofitted beams in flexure," Composite Structures, 2017, 176, pp. 268-280.

12. T. Sen, and H.J. Reddy, "Strengthening of RC beams in flexure using natural jute fibre textile reinforced composite system and its comparative study with CFRP and GFRP strengthening systems" International Journal of Sustainable Built Environment, 2013, 2(1), pp. 41-55.

13. M. Bruggi, and A. Taliercio, "Topology optimization of the fiber-reinforcement retrofitting existing structures," International Journal of Solids and Structures, 201350(1), 2013, 121-136.

14. M.I. Kabir, , M. Subhani, , R. Shrestha, and B. Samali, , 2018. Experimental and theoretical analysis of severely damaged concrete beams strengthened with CFRP. Construction and Building Materials, 178, 161-174.

15. A. Bousselham, and O. Chaallal, "Experimental investigations on the influence of size on the performance of RC T-beams retrofitted in shear with CFRP fabrics," Engineering Structures, 2013, 56, pp. 1070-1079.

16. A.N. Nayak, A. Kumari, and R.B.,Swain, "Strengthening of RC Beams Using Externally Bonded Fibre Reinforced Polymer Composites," In Structures 14, 2018, June, 137-152.

17. M. hossein Saghafi, and H. Shariatmadar, "Enhancement of seismic performance of beam-column joint connections using high performance fiber reinforced cementitious composites" Construction and Building Materials, 2018, 180, pp. 665-680.

18. A.S. Jeyabharathy, and S. Robert Ravi, "Experimental Investigation on Behavior of R.C.C Beam Retrofitted With Sisal Fibre Sheet" Journal of Innovative Research in Science, Engineering and Technology, 2(7), 2013, pp. 3159-3162.

19. T. Sen, and H.J. Reddy, "Flexural strengthening of RC beams using natural sisal and artificial carbon and glass fabric reinforced composite system," Sustainable Cities and Society, 2014, 10,pp. 195-206.

20. T. Sen, and H.J. Reddy, "A numerical study of strengthening of RCC beam using natural bamboo fibre," International Journal of Computer Theory and Engineering, 2011, 3(5), 707.

21. M. Areiza-Hurtado, and J.D. Aristizábal-Ochoa, "Elastic analysis of composite beams and beams retrofitted with FRP laminates with generalized end conditions," Engineering Structures, 2017, 147, pp. 309-315.

22. J. Duic, S. Kenno, and S. Das, "Performance of concrete beams reinforced with basalt fibre composite rebar," Construction and Building Materials, 2018, 176, pp. 470-481.
23. P. Wang, F. Sun, H. Fan, W. Li, and Y. Han, "Retrofitting scheme and experimental research of severally damaged carbon fiber reinforced lattice-core sandwich cylinder," Aerospace Science and Technology, 2016, 50, pp. 55-61.

24. M. Valente, and G. Milani, , 2018. Alternative retrofitting strategies to prevent the failure of an under-designed reinforced concrete frame. Engineering Failure Analysis, 89, 271-285.

25. M. Hüsken, Y. Jin, and B. Sendhoff, "Structure optimization of neural networks for evolutionary design optimization, Soft Computing, 2005, 9(1), 21-28.

26. K.Y. Lee, N. Chung, and S. Hwang, "Application of an artificial neural network (ANN) model for predicting mosquito abundances in urban areas," Ecological informatics, 2016, 36, pp.172-180.

27. A. Askarzadeh, "A novel metaheuristic method for solving constrained engineering optimization problems: Crow search algorithm," Computers \& Structures, 2016, 169, pp. 1-12.

28. S. Rajput, M. Parashar, , H.M. Dubey, and M. Pandit, , 2016, December. Optimization of benchmark functions and practical problems using Crow Search Algorithm. In 2016 Fifth International Conference on Eco-friendly Computing and Communication Systems (ICECCS). 73-78 IEEE.

29. H. Cai, and A.J. Aref, "A genetic algorithm-based multi-objective optimization for hybrid fiber reinforced polymeric deck and cable system of cable-stayed bridges," Structural and Multidisciplinary Optimization, 2015, 52(3), 583-594.

30. P V Anjali, P Anoop, "Finite Element Modeling of Hybrid Fibre Reinforced Concrete Beam with Elastomeric Bearing Pads", International Research Journal of Engineering and Technology, 2017, $4(5)$

\section{AUTHORS PROFILE}

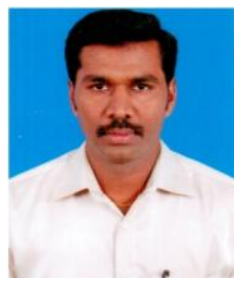

First Author: A.S.Jeyabharathy A.S.JEYABHARATHY received the B.E. degree in Civil Engineering from K.S.R College of engineering, trichencode, in 2008, and the $\mathrm{M}$. Tech Structural Engineering from Karunya University, Coimbatore, in 2010. He is a research scholar in Karunya University, Coimbatore

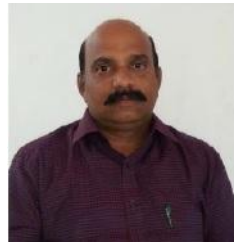

Second Author: S Robert Ravi Dr. S. ROBERT RAVI received the B.E. degree in Civil Engineering from Thiagarajar College of Engineering. Tamilnadu, the M.E Structural Engineering from Karunya University, Coimbatore. Tamilnadu, and the Ph.D.Civil Engineeringing Karunya University ,Coimbatore, Tamilnadu. He is a Professor in Department of Civil Engineering from ACE Engineering College, Ghatkesar, Hyderabad.Teaching Experience is More than 25 Years. 